\title{
EL HORIZONTE DE LA GEOMORFOLOGÍA ESTRUCTURAL EN GEOGRAFÍA: EL ÚLTIMO LEGADO DE JESÚS GARCÍA FERNÁNDEZ
}

\author{
Juan Antonio Marco Molina \\ Universitat d'Alacant
}

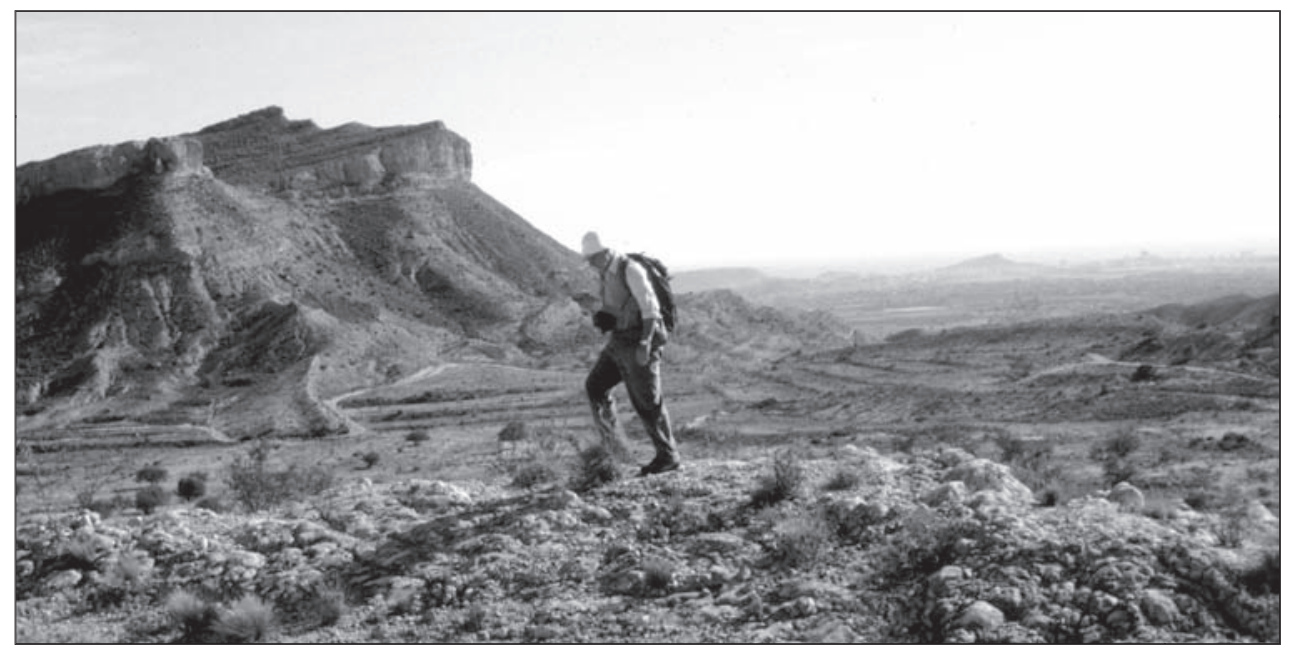

Quiero comenzar por agradecer al Departamento de Geografía de la Universidad de Valladolid el que pensara en mi para participar en este solemne acto en memoria de D. Jesús García Fernández.

Presentar su obra póstuma Geomorfología Estructural (Elementos del relieve) —subtítulo que ha desaparecido en el proceso de edición - es para mi, ante todo, un honor; pero también una responsabilidad que asumo modesta y emocionadamente.

No es mi pretensión desgranar exhaustivamente ni los contenidos, sumamente interesantes, ni los rasgos formales; aspectos que, de consuno, dotan de acusada singularidad

* Discurso pronunciado en el Homenaje al Profesor Jesús García Fernández, celebrado el 9 de noviembre de 2006, en la Universidad de Valladolid. 
y valor sin igual a este libro de 644 páginas y 442 figuras. Más bien pretendo destacar el significado de esta inédita y gran aportación al conocimiento geográfico, a esa Geografía «sin epítetos, ni preferencias», como a él gustaba subrayar.

Pero si la Geografía no precisa de epítetos, éstos, afloran de manera tan diversa como la paleta de colores del Keüper cuando se leen unas páginas, un párrafo, una frase o un voquible del libro. Es posible, aunque más bien creo que seguro, que le sucederá lo mismo a aquellos colegas con los que compartí cursos de trabajos de campo desde la edición de 1984 como José Luis Moreno, Maite Ortega, Carlos Morales, Luis Melo, Carlos Munguía, Isidro Velasco, Javier Sanz, Marta Marañón, Alfonso García, Javier Dionisio Gutiérrez o Nieves López, entre otros muchos; así como a los compañeros Enrique Matarredona, Ascensión Padilla, José María Matos y el propio Alfredo Morales que, además de en los cursos, apoyamos regularmente a D. Jesús en los trabajos de campo en tierras alicantinas. Unos y otros hemos tenido el privilegio de descubrir buena parte de los ejemplos que, en sus propias palabras, son sumamente «expresivos y cercanos al lector»; yo precisaría que, para todos nosotros, esta cercanía, resultado de haber compartido muchas horas de trabajo con él, se torna emoción.

Difícilmente olvidaremos las muchas enseñanzas, vivencias y anécdotas que depara el trabajo duro del geógrafo-geomorfólogo. Con la lectura, cada uno rememorará, sin duda con nostalgia, afecto y cariño, algún episodio. En particular, recuerdo el día de descanso durante uno de los cursos de trabajo de campo en la Cordillera Ibérica. El lugar, la Playa Pita; nuestra actividad, un placentero pedaleo en patín por el embalse hasta que el estallido de la anhelada tormenta estival, nos llevó hasta las mesas del merendero de las que, D. Jesús, no se había despegado, ni cesado en su trabajo. ¿Quién de los presentes en aquella edición de los cursos no recuerda la recompensa que nos había preparado? Mientras todos disfrutábamos de la jornada de asueto y diversión, D. Jesús preparó unos magníficos bloques diagrama en los que se explicaba, con claridad meridiana, tanto el paso del relieve conforme al inverso según ascensos y descensos del nivel de eje de los pliegues (página 409 del libro), como el esquema del sinclinal colgado de la Sierra de Carazo (página 414).

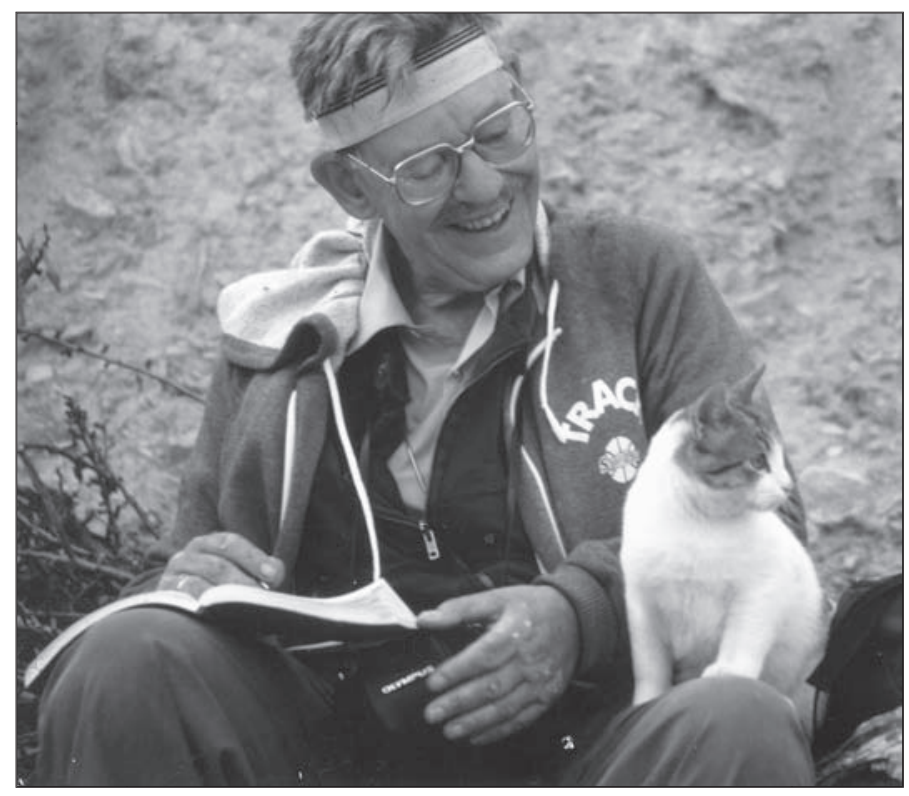


Más íntimos son los recuerdos cuando uno comprueba que contactos y disposiciones verdaderamente abracadabrantes como los del frente meridional de la Sierra de las Águilas y el oriental de la Moleta, ambas en Alicante, han sido magistralmente desvelados y elevados a la categoría de modelos-tipo. Pero más emotivos son aquellos pasajes que te retrotraen y te llevan a recordar la combustión de una aliaga para entrar en calor, los innúmeros cigarrillos de la inspiración o la imagen de una gata tricolor que encariñó a D. Jesús durante una jornada en la que soportó y obvió el dolor de una muñeca fracturada con tal de aprovechar el tiempo al máximo.

Espero que ustedes comprendan y sepan perdonar esta línea de fuga hacia la tangente emocional respecto de mi verdadero cometido en el día de hoy; pero, para muchos de nosotros, este libro también tiene ese significado.

En el plano más académico, tres son los sustantivos que voy a utilizar como hilo conductor de esta apretada reseña: fidelidad, rigor e innovación. El primero de ellos, porque, tratándose de una disciplina tan propensa a la fuga hacia otras ciencias, D. Jesús, no se ha ido por las ramas y aboga por la inserción de la Geomorfología Estructural en una Geografía General, con un claro carácter propedéutico. Demuestra, así, su fidelidad a la Geografía, en definitiva, a sus principios. No por ello reniega de la posibilidad de que la labor del geógrafo tenga como objeto principal el estudio y conocimiento del relieve. En otras publicaciones suyas ya se lamenta de lo poco o nada tratado que ha sido el relieve. El porqué de esta situación, cómo se ha llegado a ella y la necesaria revisión epistemológica para repararla, se recogen en el primer capítulo del libro. Es todo un fundado alegato a favor de una geomorfología unitaria con una concepción geográfica y enteramente desligada de servidumbres geológicas.

Con este libro también demuestra fidelidad a una de sus máximas: siempre había dicho que era preciso trabajar en lo realmente importante, no en lo que convenía; y él era consciente que este libro lo tenía que abordar; era una deuda que se debía a sí mismo y que otros muchos le exigíamos insistentemente.

Pero si esta obra es fiel a algo, es a su manera de abordar cualquier tema, es decir, desde la observación y el contacto directo con la realidad; según él, el mejor modo de contrastar los modelos teóricos y comprobar si casan con aquella. Probablemente por ello, el libro que hoy se presenta escapa a la clasificación del mismo como manual; no se si sería más apropiado referirse a él como un tratado de Geomorfología Estructural. Lo que sí es cierto es que aúna las virtudes académicas y propedéuticas de un manual, con las excelencias de un trabajo de investigación. A nadie debe escapar que esta Geomorfología Estructural se basa, sobre todo, en los resultados de las investigaciones realizadas por D. Jesús sobre los distintos tipos de relieve. Así, los modelos teóricos van acompañados de ejemplos concretos, muchos de los cuales son inéditos e, insisto, fruto de la actividad que, sin duda, le resultaba más gratificante: los trabajos de campo a los que nunca dio tregua y en los que no desfalleció. En cierto modo, se entiende así que, sólo cuando la condición física y la salud le impidieron desarrollar esta actividad, abordase la elaboración de esta magna obra de la que también he destacado el rigor.

Obviamente, con este sustantivo no me refiero a excesiva severidad, sino a propiedad y precisión. Me refiero al cultivo del léxico que desarrolló a lo largo de su trayectoria rescatando y descubriendo, para muchos de nosotros, el enorme caudal de voces que enriquece sus escritos y que sabiamente ha trasladado a la terminología geomorfológica. En este sentido, resulta muy valiosa la revisión de numerosos términos sumidos en el limbo de la confusión, así como el destierro de otros que, procedentes de otros idiomas, resultaban inexpresivos y hasta inanes, siendo sustituidos por vocablos del castellano, mucho más rico en matices. Aportaciones que, estando presentes en toda la obra, son explícitas 
en el capítulo 4, dedicado a las estructuras plegadas, y en el 6, relativo a los elementos del relieve plegado y sus tipos.

Pero si la precisión terminológica es una constante a lo largo de todo el libro, más importante, si cabe, es su proyección en los contenidos y el modo en que se desarrollan. Así, los capítulos 3 y 4, sobre estructuras plegadas y falladas respectivamente, se conciben como un fundamento necesario que faculte al lector para comprender tanto el relieve plegado como el fallado, recogidos en los capítulos 6 y 7. Por su parte, el capítulo 5, dedicado a las estructuras perforantes, recibe un tratamiento unitario en el que, lo que hasta ahora no había merecido más consideración que la de meros accidentes tectónicos, adquiere un papel destacado en el repertorio de elementos del relieve, de morfoestructuras e, incluso, como factor de su configuración. Se aprecia, pues, cómo desde el rigor, se llega a un planteamiento novedoso. Y es ese el tercer sustantivo señalado con anterioridad, la innovación.

El libro en su conjunto, como ya se ha indicado a suso, está repleto de aportaciones inéditas sobre el relieve de amplios sectores de la Cordillera Cantábrica, la Cordillera Ibérica y la Bética; tienen, por tanto, todo de novedoso. Sin embargo, la verdadera innovación no se limita al dar a conocer hechos particulares, sino en elevarlos a la categoría de conceptos generales y en ahirmarlos en la concepción de teorías sobre la formación del relieve.

En el haber de sus trabajos en la Cordillera Bética merecen ser destacadas algunas novedades en la terminología específica de las estructuras falladas (capítulo 3). De ellas, sólo mencionaré las llamadas «fallas contradictorias»; calificativo que troqueló para referirse a aquellos contactos mecánicos que, en un primer reconocimiento, atarantan a uno por la contradicción aparente entre las relaciones estratigráficas de los materiales implicados en la falla y el movimiento relativo de los bloques inducido a partir de los desniveles provocados por aquella y la disposición de los ganchos. Basándose en hechos reales elabora un modelo teórico, recogido en la página 121, en el que parte de una estructura plegada y arrasada previa, a la que superpone la deformación definitiva de las fallas.

Sin embargo, la novedad no se agota en este ejemplo. Si en el relieve plegado son más conocidos sus repertorios de elementos-tipo (capítulo 6), introduce una auténtica revolución conceptual y terminológica al respecto de los elementos del relieve fallado en coberteras sedimentarias (capítulo 7). Revolución que tiene como principales fundamentos la ruptura con las ataduras geológicas y la búsqueda de expresividad conceptual; esta última, como no podía ser de otro modo, basada en el dominio del lenguaje. Por sí mismo, este aspecto nomenclatural, merecería un glosario o, al menos, un índice de materias del que carece el libro; el cual, junto a una selección de láminas, que me consta había realizado D. Jesús, completaría su concepción de este manual.

De mayor trascendencia para el avance del conocimiento son sus ideas sobre la formación del relieve. Muy destacados son sus planteamientos sobre la mecánica tectónica de los pliegues perforantes, los diapiros y las estructuras diapíricas. Especialmente apodícticos son los esquemas interpretativos sobre el origen, evolución y remanencia de las perforaciones en las fajas diapíricas; concepto que, dicho sea de paso, también acuñó. Pero donde se produce un abrumador despliegue de argumentos y un avance sustancial es en la revisión y enunciado de sus ideas o teoría sobre la formación del relieve plegado.

Desde las teorías tradicionales y el relieve invertido, pasando por el concepto de relieve inverso introducido por Tricart, D. Jesús, sienta las bases para entender el relieve plegado a partir de una evolución morfotectónica, sobre todo, del relieve inverso, sin descartar la evidencia de sectores en los que la evolución ha sido morfoestática. Los mecanismos intrusivos y diapíricos mencionados se integran en una explicación en la que procesos tectónicos y erosivos interactúan, de manera que los primeros determinan a los segundos, pero, en la evolución, estos últimos también condicionan la tectónica y, ésta, a su vez, ha 
guiado la erosión posterior. De este modo, el paradigma de la morfogénesis propuesto por Tricart, es sustituido por el de morfotectónica magistralmente explicado por el profesor García Fernández en este libro.

Y, si todo ello no es suficiente, quiero recordar que el verdadero legado que D. Jesús nos hace con este libro está en el primer capítulo, en su manera de entender la Geomorfología sin epítetos y como algo indisociable de la Geografía, incluso, desde la concepción antropocéntrica de la misma que él defendía.

Se trata, obviamente, de una postura con planteamientos no exentos de provocación, lo mismo que los últimos artículos que publicó en la revista Investigaciones Geográficas sobre el papel de la Biogeografía o la posición de la Geografía Física, que levantaron acaloradas polémicas y provocaron duras críticas, pero que, estoy convencido, han contribuido a decidir el rumbo centrípeto de muchos geógrafos que, a través de la exacerbada especialización, casi habían renegado de su formación inicial.

Con todo, espero que esta herencia sirva para conseguir la palingenesia de la Geomorfología Estructural desde la Geografía, tan ansiada por D. Jesús García Fernández. 